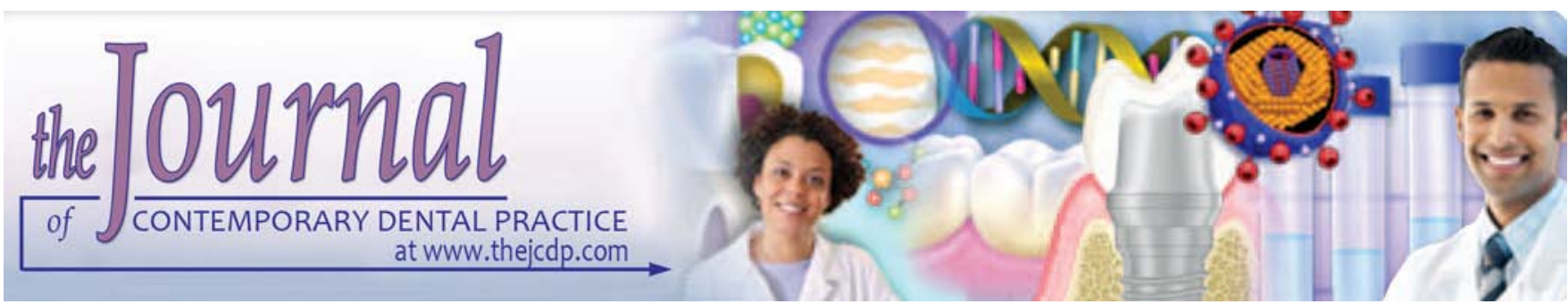

\title{
Effect of Instrumentation Techniques, Irrigant Solutions and Artificial accelerated Aging on Fiberglass Post Bond Strength to Intraradicular Dentin
}

${ }^{1}$ Fernanda Ribeiro Santana, ${ }^{2}$ Carlos José Soares, ${ }^{3}$ Júlio Almeida Silva, ${ }^{4}$ Ana Helena Gonçalves Alencar

${ }^{5}$ Sara Rodrigues Renovato, ${ }^{6}$ Lawrence Gonzaga Lopes, ${ }^{7}$ Carlos Estrela

\begin{abstract}
Objective: To evaluate the effect of instrumentation techniques, irrigant solutions and specimen aging on fiberglass posts bond strength to intraradicular dentine.

Materials and methods: A total of 120 bovine teeth were prepared and randomized into control and experimental groups resulting from three study factors (instrumentation techniques, irrigant solutions, specimen aging). Posts were cemented with RelyX U100. Samples were submitted to push-out test and failure mode was evaluated under a confocal microscope.
\end{abstract}

Results: In specimens submitted to water artificial aging, nickel-titanium rotary instruments group presented higher bond strength values in apical third irrigated with $\mathrm{NaOCl}$ or chlorhexidine. Irrigation with $\mathrm{NaOCl}$ resulted in higher bond strength than ozonated water. Artificial aging resulted in significant bond strength increase. Adhesive cement-dentin failure was prevalent in all the groups.

Conclusion: Root canal preparation with NiTi instruments associated with $\mathrm{NaOCl}$ irrigation and ethylenediaminetetra acetic acid (EDTA) increased bond strength of fiberglass posts cemented with self-adhesive resin cement to intraradicular dentine. Water artificial aging significantly increased postretention.

\footnotetext{
1,3-5,7 Department of Stomatologic Sciences, School of Dentistry Federal University of Goiás, GO, Brazil

${ }^{2}$ Department of Dental Materials and Operative Dentistry School of Dentistry, Federal University of Uberlândia, Uberlândia MG Brazil

${ }^{6}$ Department of Prevention and Oral Rehabilitation, School of Dentistry, Federal University of Goiás, GO, Brazil

Corresponding Author: Carlos Estrela, Professor, Department of Stomatologic Sciences, Federal University of Goiás, Praça Universitária s/n, Sector Universitário CEP: 74605-220 Goiânia, GO, Brazil, e-mail: estrela3@terra.com.br
}

Clinical significance: The understanding of factors that may influence the optimal bond between post-cement and cementdentin are essential to the success of endodontically treated tooth restoration.

Keywords: Aging, Bond strength, Fiberglass post, Irrigant, Root dentin.

How to cite this article: Santana FR, Soares CJ, Silva JA, Alencar AHG, Renovato SR, Lopes LG, Estrela C. Effect of Instrumentation Techniques, Irrigant Solutions and Artificial accelerated Aging on Fiberglass Post Bond Strength to Intraradicular Dentin. J Contemp Dent Pract 2015;16(7): 523-530

Source of support: Nil

Conflict of interest: None

\section{INTRODUCTION}

Endodontically treated teeth frequently require indirect restorations because of extensive loss of tooth structure as a result of caries lesions, previous restorations and/or fractures. Thus, it is required the use of a post to provide sufficient retention for the final restoration. ${ }^{1-3}$

Fiberglass posts, in combination with composite core foundation materials, are widely accepted as alternative to cast posts in the restoration of endodontically treated teeth (ETT). ${ }^{1-4}$ Fiberglass posts have a high flexural strength and elasticity modulus, similar to that of dentine, which minimize the transmission of stresses to root canal walls and decrease the possibility of fractures. ${ }^{2,5}$ Furthermore, they can also be cemented in the root canal using adhesive techniques. ${ }^{4,6}$

An optimal bond between post-cement and cementdentin is necessary for the success of the restorative procedure in ETT. ${ }^{7}$ However, debonding is the most common mode of failure of the fiber-reinforced composite post restoration. ${ }^{1,8,9}$ This fact occurs probably to poor 
visibility, anatomical features and limited capacity to dissipate polymerization shrinkage stresses in long narrow post spaces, exhibiting a highly unfavorable configuration factor, and was found to be less effective than bonding to coronal dentin. ${ }^{2,10-15}$

Endodontic treatment performed before the luting of posts also may interfere with bonding to intraradicular dentin. ${ }^{11,12,16-19}$ The sanitizing process of infected root canals begins with the mechanical action of endodontic instruments and chemical action of irrigants, which can induce chemical and structural changes of dentine surface and affect the interaction with restorative materials. ${ }^{1,6,9,18,20}$

An effective irrigating solution in root canal preparation (RCP) is essential for the sanitization process, because it favors cleaning, shaping and neutralizes necrotic pulp content. Several irrigant solutions for RCP have been proposed. Sodium hypochlorite and chlorhexidine are antimicrobial agents frequently used for root canal infections treatment. ${ }^{20}$ The use of ozonated water $\left(\mathrm{O}_{3}\right)$ has been studied as an alternative method for the disinfection of the root canal treatment. ${ }^{12,20}$

Nonetheless, there is no consensus in the literature about the possible effects of the chemical agents commonly used during RCP regarding bonding to intraradicular dentine, since these depend on the dentin bonding system used. ${ }^{11-13,16-19}$ Thus, the compatibility among different materials used in root canal treatment and in luting fiber posts to root dentine is an important aspect to be considered for a successful restoration.

This study analyzed the effects of root canal treatment (instrumentation technique and irrigant solution), and specimen artificial accelerated aging on bond strength of fiber posts adhesively cemented to root canals of bovine incisors, to test whether these factors had any effect on fiber post bond strength to root dentine, according to the different regions of the post space (cervical, middle, apical). The null hypothesis tested was that the instrumentation techniques, the irrigant solutions and the specimen artificial accelerated aging have no influence on fiberrglass post regional bond strength to intraradicular dentin.

\section{MATERIALS AND METHODS}

A total of 120 freshly extracted bovine incisors with roots that were anatomically similar in size, shape and had a canal less than $1 \mathrm{~mm}$ in diameter and fully developed apices, were selected from 700 teeth and stored in distilled water. Each tooth was decoronated using a double-faced diamond disk (KG Soresen, São Paulo, SP, Brazil), operated perpendicularly to its longitudinal axis to produce roots $15 \mathrm{~mm}$ long. Roots were randomly divided into 12 groups $(n=10)$ resulting from the interaction among three study factors: instrumentation technique-root canal preparation (RCP) with stainless steel instruments, K-File ${ }^{\circledR}(\mathrm{SS})$ and RCP with $\mathrm{K} 3{ }^{\circledR}$ nickeltitanium rotary instruments (NiTi); irrigant solutions-1\% sodium hypochlorite $(\mathrm{NaOCl}), 2 \%$ chlorhexidine $(\mathrm{CHX})$ and $1.2 \%$ ozonated water $\left(\mathrm{O}_{3}\right)$; specimen aging — test with no aging (immediate) and test performed after artificial accelerated aging with 2 months of water storage at $37^{\circ} \mathrm{C}$ (aged).

\section{Endodontic Procedures}

Root canals were prepared to $1 \mathrm{~mm}$ short of the apex using a crown-down technique. In groups SS, RCP was carried out using sizes \# 1,2 Gates glidden burs (Dentsply Maillefer, Ballaigues, Switzerland) (working length 'WL' = $10 \mathrm{~mm}$ ), size \# 2 Largo burs (Dentsply Maillefer) $(\mathrm{WL}=10 \mathrm{~mm})$, and stainless steel instruments (K-File; Dentsply Maillefer) up to \# $45 \mathrm{~K}$-File (WL = $14 \mathrm{~mm}$ ). In groups NiTi, root canals were prepared with sizes \# 1,2 Gates glidden burs (Dentsply Maillefer) (WL = $10 \mathrm{~mm}$ ) and K3 nickel-titanium rotary instruments (SybronEndo, Optimum, São Paulo, Brazil) in the following sequence: \# 25.10 taper $(\mathrm{WL}=10 \mathrm{~mm})$; \# 15-25.02 taper $(\mathrm{WL}=14 \mathrm{~mm})$; \# 25.04 taper $(W L=14 \mathrm{~mm})$; \# 25.06 taper $(W L=14 \mathrm{~mm})$; \# 30-45.02 taper (WL = $14 \mathrm{~mm})$.

During RCP, at each change of instrument, root canals were irrigated with $2 \mathrm{ml}$ of one of the irrigant solutions: NaOCl: 1\% sodium hypochlorite (Fitofarma, Goiânia, GO, Brazil); CHX: 2\% chlorhexidine (Fitofarma, Goiânia, GO, Brazil); $\mathrm{O}_{3}: 1.2 \%$ ozonated water. Ozone was produced by electric discharge through oxygen current (PXZ3507, Eaglesat Tecnologia em Sistemas Ltd., São José dos Campos, SP, Brazil), and bubbled into $1 \mathrm{~L}$ sterile distilled water at $7 \mathrm{gm} / \mathrm{h}$ ozone flow rate $(1.2 \%) .{ }^{20}$ In all groups, $3 \mathrm{ml}$ of $17 \%$ ethylenediaminetetraacetic acid (EDTA) (Biodinâmica Química e Farmacêutica Ltda., Ibiporã, PR, Brazil) was used for 5 minutes to remove the smear layer. The final irrigation was performed with $5 \mathrm{ml}$ of the same solution used. After RCP, root canals were not filled to avoid interference of the filling material in the analysis of adhesion as shown in previous studies. $6,19,33$

\section{Post Space Preparation}

Post space was prepared using sizes \# 3 to 5 Largo burs (Dentsply Maillefer) (WL = $10 \mathrm{~mm}$ ), which corresponded to $1.5 \mathrm{~mm}$ parallel-sided, serrated fiber post (Reforpost \# 3; Angelus, Londrina, PR, Brazil). Root canals were irrigated, at each change of burs and at the end of the preparation, with $2 \mathrm{ml}$ of the same endodontic irrigant 
used previously and dried with absorbent paper points. All roots were covered externally with utility wax to avoid lateral activation by light source. ${ }^{3}$

\section{Post Luting Procedure}

Fiberglass posts were cleaned with $70 \%$ alcohol, then in a single application using a microbrush and, after drying, a silane agent was applied for 1 minute (Silano; Angelus). The self-adhesive resin cement (RelyX U100; 3M-ESPE, St Paul, MN, USA) was prepared according to the manufacturer's instructions, introduced into the canal using a K-File and placed on the post. The post was seated to full depth by finger pressure. Excess cement was removed after 1 minute. After 5 minutes, the resin cement was light-cured using a $1200 \mathrm{~mW} / \mathrm{cm}^{2}$ (Radii-Cal; SDI, Bayswater, Australia) source for 40 seconds each on the cervical face of the root, in the direction of the long axis of the root, and obliquely to the buccal and lingual surfaces, for a total of 120 seconds. The coronal limit of the interface between the post-cement dentin was then sealed using composite resin, and the roots were stored in distilled water at $37^{\circ} \mathrm{C}$ for 24 hours. The samples were stored for 24 hours until the resin cement had completely settled, because it is a dual cement, which after activation with curing needs a time to promote complete chemical setting.

\section{Specimen Preparation for Push-out Test}

After 24 hours, each root was serially sectioned perpendicular to its long axis using a double-faced diamond disc (102.0 mm Diameter $\times 0.3 \mathrm{~mm}$ Thickness $\times 12.7 \mathrm{~mm}$ Arbor, Extec, Enfield, CT, USA) and a precision saw (Isomet 1000, Buehler, Lake Bluff, IL, USA) at low speed under water cooling to obtain two slices measuring $1 \mathrm{~mm}$ thick from cervical, middle and apical post thirds, a total of six slices per root.

\section{Push-out Test}

In immediate groups, slices were submitted immediately (with no aging) to a push-out test; while in aged groups, slices were stored in distilled water at $37^{\circ} \mathrm{C}$ for 2 months (artificial accelerated aging) prior to testing. The pushout test was performed in a testing machine (EMIC DL 2000, São José dos Pinhais, PR, Brazil) by applying a compressive load at $0.5 \mathrm{~mm} / \mathrm{min}$ from the apical to coronal direction until failure. The bond strength was calculated in MPa by dividing the load at failure $(\mathrm{N})$ by the area of the bonded interface. The area of the bonded interface was calculated as follows: $A=2 \pi \mathrm{rh}$, where $\mathrm{A}$ is the area of the bonded interface, $\pi=3.14, \mathrm{r}$ is the radius of the post segment $(\mathrm{mm})$ and $\mathrm{h}$ is the thickness of the post segment (mm). $3,7,14$

\section{STATISTICAL ANALYSIS}

The Statistical Analysis Software (SAS) (version 9.2, SAS Institute Inc., Cary, NC, USA) was used for statistical analysis. The Shapiro-Wilk test was used to test normality. The effects of instrumentation technique, irrigant solutions and post thirds on bond strength were analyzed using two-way analysis of variance (ANOVA) in a splitplot arrangement, with the main plot for instrumentation technique and irrigant solutions, and the subplot for post third (cervical, middle and apical). Comparisons with respect the artificial aging was performed by one-way ANOVA with the main plot for this factor and the subplot for post third. The Tukey's test was used for multiple comparisons $(\alpha=0.05)$.

\section{Confocal Microscopy}

To determine failure mode, all fractured specimens were only air dried and analyzed under a confocal laser scanning microscope (Carl Zeiss Laser Scanning Systems, LSM510, META, Oberkochen, Germany). Images were analyzed using the Zeiss LSM Image Browser (META, Germany). The failure mode was classified into six types: (I) adhesive between the post and resin cement; (II) adhesive between resin cement and intraradicular dentine; (III) cohesive in cement; (IV) cohesive in dentine; (V) cohesive in post, and (VI) mixed, among post, resin cement and intraradicular dentine. ${ }^{4,21}$

\section{RESULTS}

Mean push-out bond strengths and standard deviations of immediate groups are shown in Table 1. Two-way ANOVA (instrumentation technique $\times$ irrigant solutions) with subplot (post third) of immediate groups showed a significant difference for irrigant solutions $(p=0.0023)$ and post third ( $\mathrm{p} \leq 0.0001)$. Tukey's test indicated that irrigation with $\mathrm{NaOCl}$ resulted in higher bond strength than with $\mathrm{O}_{3}$, except in the apical third of NiTi that was similar. The irrigation with $\mathrm{CHX}$ resulted on intermediate values that were statistically similar to values obtained in groups irrigated with $\mathrm{O}_{3}$ in thirds cervical/apical of SS and cervical/middle of NiTi, and in all groups irrigated with $\mathrm{NaOCl}$. Regardless of RCP and irrigant solutions, cervical third had higher bond strength values than apical third.

Mean push-out bond strengths and standard deviations of aged groups are shown in Table 2. Two-way ANOVA (instrumentation technique $\times$ irrigant solutions) with subplot (post third) of aged groups showed significant difference for instrumentation technique $(p=0.0356)$, irrigant solutions ( $\mathrm{p} \leq 0.0001)$, post third $(\mathrm{p} \leq 0.0001)$ and the interaction between irrigant and post third ( $p=0.0047)$. 
In apical third of specimens irrigated with $\mathrm{NaOCl}$ or $\mathrm{CHX}$, NiTi resulted on higher bond strength than SS. Regarding the irrigant solution, $\mathrm{NaOCl}$ resulted on higher bond strength values than $\mathrm{O}_{3}$ in all the groups. Chlorhexidine presented statistically lower value than $\mathrm{NaOCl}$ only in cervical third of $\mathrm{SS}$ and similarity to $\mathrm{NaOCl}$ in the other groups. Cervical third presented higher values than apical third, except in groups NiTi-NaOCl and NiTi-CHX, which were similar.

Mean push-out bond strengths and standard deviations as a result of specimen aging and post third of all groups are in Table 3. One-way ANOVA (artificial aging) with subplot (post third) in group SS-NaOCl showed significance for artificial aging $(\mathrm{p}<0.001)$ and post third $(p<0.001)$. In group SS-CHX there was significance for artificial aging $(\mathrm{p}<0.001)$ and post third $(\mathrm{p}<0.001)$. In group $\mathrm{SS}-\mathrm{O}_{3}$ there was significance for artificial aging $(p=0.006)$, post third $(p<0.001)$ and interaction between the factors $(p=0.032)$. In group NiTi-NaOCl there was significance for artificial aging $(\mathrm{p}<0.001)$ and post third $(\mathrm{p}=0.005)$. In group NiTi-CHX there was significance for artificial aging $(\mathrm{p}<0.001)$ and post third $(\mathrm{p}=0.008)$.

Table 1: Bond strength means in MPa (standard deviation) of immediate groups (no aging) and statistical categories defined by Tukey's test $(\mathrm{n}=10)$

\begin{tabular}{|c|c|c|c|c|c|c|c|}
\hline \multicolumn{8}{|c|}{ Instrumentation technique } \\
\hline \multirow{3}{*}{$\begin{array}{l}\text { Irrigant } \\
\text { solution }\end{array}$} & \multicolumn{3}{|c|}{ Stainless steel instrument } & \multicolumn{2}{|c|}{ Nickel-titanium instrument } & & \multirow[b]{3}{*}{ Total } \\
\hline & \multicolumn{3}{|c|}{ Post third } & \multicolumn{3}{|c|}{ Post third } & \\
\hline & Cervical & Middle & Apical & Cervical & Middle & Apical & \\
\hline $1 \% \mathrm{NaOCl}$ & $12.9(2.4)^{\mathrm{Aa}}$ & $10.3(4.0)^{\mathrm{Ba}}$ & $7.10(3.8)^{\mathrm{Ca}}$ & $13.5(2.1)^{\mathrm{Aa}}$ & $11.4(3.3)^{\mathrm{ABa}}$ & $9.3(4.8)^{\mathrm{BCa}}$ & $10.8(4.0)^{\mathrm{a}}$ \\
\hline $2 \% \mathrm{CHX}$ & $11.4(3.3)^{\mathrm{Aab}}$ & $9.8(3.9)^{\mathrm{ABa}}$ & $6.7(3.9)^{\mathrm{Cab}}$ & $11.5(3.8)^{\mathrm{Aab}}$ & $10.0(4.9)^{\mathrm{ABab}}$ & $7.1(5.6)^{\mathrm{BCa}}$ & $9.4(4.5)^{a b}$ \\
\hline Ozone water & $8.7(6.8)^{\mathrm{Ab}}$ & $6.2(5.0)^{\mathrm{Bb}}$ & $3.5(2.9)^{\mathrm{Cb}}$ & $9.5(3.4)^{\mathrm{Ab}}$ & $7.4(1.6)^{\mathrm{ABb}}$ & $6.8(1.4)^{\mathrm{BCa}}$ & $7.0(4.3)^{\mathrm{b}}$ \\
\hline Total & $8.5(4.9)^{\mathrm{B}}$ & $9.6(4.2)^{\mathrm{A}}$ & & & & & \\
\hline
\end{tabular}

Capital letters were used to compare groups in the horizontal lines and lower-case letters were used to compare groups in the vertical lines. Tukey categories with same letters are not statistically significant from each other $(p<0.05)$; Stainless steel instruments-K-file; NiTi: K3 nickel-titanium instruments

Table 2: Bond strength means in MPa (standard deviation) of aged groups and statistical categories defined by Tukey's test $(n=10)$

\begin{tabular}{|c|c|c|c|c|c|c|c|}
\hline \multicolumn{8}{|c|}{ Instrumentation technique } \\
\hline \multirow{3}{*}{$\begin{array}{l}\text { Irrigant } \\
\text { solution }\end{array}$} & \multicolumn{3}{|c|}{ Stainless steel instrument } & \multicolumn{3}{|c|}{ Nickel-titanium instrument } & \multirow[b]{3}{*}{ Total } \\
\hline & \multicolumn{3}{|c|}{ Post third } & \multicolumn{3}{|c|}{ Post third } & \\
\hline & Cervical & Middle & Apical & Cervical & Middle & Apical & \\
\hline $1 \% \mathrm{NaOCl}$ & $24.1(5.8)^{\mathrm{Aa}}$ & $20.3(7.7)^{\mathrm{Ba}}$ & $15.5(8.6)^{\mathrm{Ca}}$ & $25.1(6.4)^{\mathrm{Aa}}$ & $22.6(6.1)^{\mathrm{ABa}}$ & $21.6(6.3)^{\mathrm{ABa}}$ & $21.5(7.3)^{a}$ \\
\hline $2 \% \mathrm{CHX}$ & $18.9(4.3)^{\mathrm{ABb}}$ & $16.2(4.0)^{\mathrm{Ba}}$ & $13.3(7.2)^{\mathrm{Ca}}$ & $21.4(3.4)^{\text {Aab }}$ & $20.8(6.3)^{\mathrm{ABa}}$ & $18.4(7.7)^{\mathrm{ABa}}$ & $18.2(6.1)^{\mathrm{a}}$ \\
\hline Ozone water & $17.4(4.9)^{\mathrm{Ab}}$ & $9.9(4.0)^{\mathrm{Bb}}$ & $6.4(3.4)^{\mathrm{Cb}}$ & $17.4(4.9)^{\mathrm{Ab}}$ & $11.0(5.3)^{\mathrm{Bb}}$ & $7.1(3.8)^{\mathrm{BCb}}$ & $11.5(6.2)^{b}$ \\
\hline Total & $15.8(7.5)^{\mathrm{B}}$ & $18.4(7.8)^{\mathrm{A}}$ & & & & & \\
\hline
\end{tabular}

Capital letters were used to compare groups in the horizontal lines and lower-case letters were used to compare groups in the vertical lines. Tukey categories with same letters are not statistically significant from each other $(p<0.05)$; Stainless steel instruments-K-file; NiTi: K3 nickel-titanium instruments

Table 3: Bond strength means in MPa (standard deviation), as a result of artificial accelerated aging and post third, and statistical categories defined by Tukey's test for each group $(n=10)$

\begin{tabular}{|c|c|c|c|c|}
\hline \multirow[b]{2}{*}{ Groups } & \multirow[b]{2}{*}{ Test } & \multicolumn{3}{|c|}{ Post third } \\
\hline & & Cervical & Middle & Apical \\
\hline \multirow[t]{2}{*}{ SS-NaOCl } & Immediate & $12.9(2.4)^{\mathrm{Ab}}$ & $10.3(4.0)^{\mathrm{ABb}}$ & $7.1(3.8)^{\mathrm{Bb}}$ \\
\hline & Aged & $24.1(5.8)^{\mathrm{Aa}}$ & $20.3(7.7)^{\mathrm{Ba}}$ & $15.5(8.6)^{\mathrm{Ca}}$ \\
\hline \multirow[t]{2}{*}{ SS-CHX } & Immediate & $11.4(3.3)^{\mathrm{Ab}}$ & $9.8(3.9)^{\mathrm{ABb}}$ & $6.7(3.9)^{\mathrm{Bb}}$ \\
\hline & Aged & $18.8(4.3)^{\mathrm{Aa}}$ & $16.2(4.0)^{\mathrm{ABa}}$ & $13.3(7.2)^{\mathrm{Ba}}$ \\
\hline \multirow[t]{2}{*}{$\mathrm{SS}-\mathrm{O}_{3}$} & Immediate & $8.7(6.8)^{A b}$ & $6.2(5.0)^{\mathrm{ABa}}$ & $3.5(2.9)^{\mathrm{Ba}}$ \\
\hline & Aged & $17.4(4.9)^{\mathrm{Aa}}$ & $9.9(4.0)^{\mathrm{Ba}}$ & $6.4(3.4)^{\mathrm{Ba}}$ \\
\hline \multirow[t]{2}{*}{$\mathrm{NiTi}-\mathrm{NaOCl}$} & Immediate & $13.5(2.1)^{\mathrm{Ab}}$ & $11.4(3.3)^{\mathrm{ABb}}$ & $9.3(4.8)^{\mathrm{Bb}}$ \\
\hline & Aged & $25.1(6.4)^{\mathrm{Aa}}$ & $22.6(6.1)^{\mathrm{Aa}}$ & $21.6(6.3)^{\mathrm{Aa}}$ \\
\hline \multirow[t]{2}{*}{ NiTi-CHX } & Immediate & $11.5(3.8)^{\mathrm{Ab}}$ & $10.0(4.9)^{\mathrm{ABb}}$ & $7.1(5.6)^{\mathrm{Bb}}$ \\
\hline & Aged & $21.4(3.4)^{\mathrm{Aa}}$ & $20.8(6.3)^{\mathrm{Aa}}$ & $18.4(7.7)^{\mathrm{Aa}}$ \\
\hline \multirow[t]{2}{*}{$\mathrm{NiTi}-\mathrm{O}_{3}$} & Immediate & $9.5(3.4)^{\mathrm{Ab}}$ & $7.4(1.6)^{\mathrm{ABb}}$ & $6.8(1.4)^{\mathrm{Ba}}$ \\
\hline & Aged & $17.4(4.9)^{\mathrm{Aa}}$ & $11.0(5.3)^{\mathrm{Ba}}$ & $7.1(3.8)^{\mathrm{Ca}}$ \\
\hline
\end{tabular}

In each group, capital letters were used to compare values in the horizontal lines and lower-case letters were used to compare values in the vertical lines. Tukey categories with same letters are not statistically significant from each other $(p<0.05)$; SS: Root canal preparation with stainless steel instruments-K-file; NiTi: Root canal preparation with K3 nickel-titanium instruments; NaOCl: $1 \%$ sodium hypochlorite; CHX: $2 \%$ chlorhexidine; $\mathrm{O}_{3}-1.2 \%$ ozonated water 
In group $\mathrm{NiTi}-\mathrm{O}_{3}$ there was significance for artificial aging $(\mathrm{p}=0.008)$, post third $(\mathrm{p}<0.001)$ and interaction between the factors $(\mathrm{p}<0.001)$. Tukey's test demonstrated a significant bond strength increase after artificial accelerated aging, except for middle and apical thirds of $\mathrm{SS}_{-} \mathrm{O}_{3}$ and apical of $\mathrm{NiTi}-\mathrm{O}_{3}$, which was similar.

Failure distribution is shown in Table 4 and Figures $1 \mathrm{~A}$ to F. Adhesive cement-dentin failure was prevalent in all groups.

\section{DISCUSSION}

The null hypotheses tested on this study were rejected. The root canal instrumentation techniques, the irrigants solutions and the artificial accelerated aging of samples affected the bond strength of fiber posts to root dentine. Moreover, bonding varied according to the different thirds of the post space.

Various mechanical methods have been used for $e x$ vivo measurement of the bond strength of fiberglass post to intraradicular dentine, as microtensile bond strength and push-out tests. ${ }^{7}$ The push-out method was shown to have fewer premature specimen failures, lower data distribution variability and a more homogenous stress distribution as compared to microtensile method during the bond strength evaluation of fiberglass posts to intraradicular dentine. ${ }^{7,14}$ The push-out laboratory test would seem to be a more appropriate methodology for the evaluation of fiberglass posts bonded to intraradicular dentine. $^{7}$

The adhesive properties of the self-etch self-adhesive resin cement RelyX U100 used in the present study, which is chemically identical to the RelyX Unicem (3M-ESPE) differing only in the application procedure, is claimed to be based upon acidic monomers that demineralize and infiltrate the tooth substrate, and create micromechanical
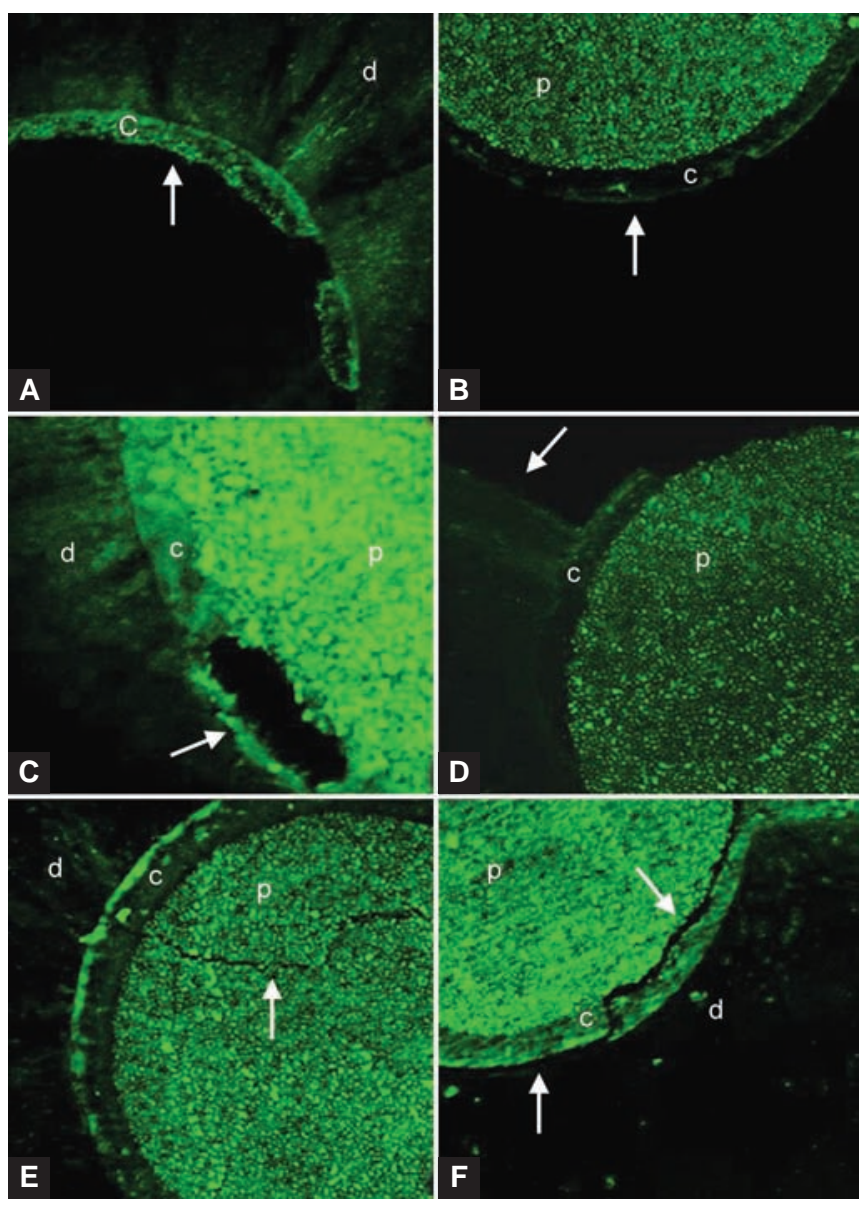

Figs $1 \mathrm{~A}$ to $\mathrm{F}$ : Microscopic images of failure mode after push-out test (magnification 10x): (A) adhesive between the post and resin cement, (B) adhesive between resin cement and intraradicular dentin; (C) cohesive in cement, (D) cohesive in dentin, (E) cohesive in post and $(F)$ mixed among post, resin cement and intraradicular dentin. Arrows point to failure region (d: dentin; c: resin cement; $\mathrm{p}$ : fiberglass post)

retention and chemical adhesion to hydroxyapatite. 4,6,22-24 Although this cement contains multifunctional hydrophilic monomers with phosphoric acid groups, it shows a low demineralization effect with a superficial morpho-

Table 4: Failure mode (\%) for experimental groups

\begin{tabular}{|c|c|c|c|c|c|c|}
\hline Groups & $\begin{array}{l}\text { Adhesive: post } \\
\text { and cement (I) }\end{array}$ & $\begin{array}{l}\text { Adhesive: cement and } \\
\text { dentin (II) }\end{array}$ & $\begin{array}{l}\text { Cohesive: } \\
\text { cement (III) }\end{array}$ & $\begin{array}{l}\text { Cohesive: dentin } \\
\text { (IV) }\end{array}$ & $\begin{array}{l}\text { Cohesive: post } \\
(V)\end{array}$ & Mixed (VI) \\
\hline SS-NaOCl immediate & - & $32(53.3)$ & - & $4(6.7)$ & $1(1.7)$ & $23(38.3)$ \\
\hline SS-CHX immediate & $1(1.7)$ & $33(55.0)$ & - & $3(5.0)$ & $1(1.7)$ & $22(36.7)$ \\
\hline $\mathrm{SS}-\mathrm{O}_{3}$ immediate & $3(5.0)$ & $33(55.0)$ & - & - & $1(1.7)$ & $23(38.3)$ \\
\hline $\mathrm{NiTi}-\mathrm{NaOCl}$ immediate & $2(3.3)$ & $33(55.0)$ & - & $6(10.0)$ & $2(3.3)$ & $17(28.3)$ \\
\hline NiTi-CHX immediate & $2(3.3)$ & $34(56.7)$ & - & $2(3.3)$ & $2(3.3)$ & $20(33.3)$ \\
\hline $\mathrm{NiTi}-\mathrm{O}_{3}$ immediate & $2(3.3)$ & $47(78.3)$ & - & $1(1.7)$ & - & $10(16.7)$ \\
\hline SS-NaOCl aged & $2(3.3)$ & $27(45.0)$ & - & - & $11(18.3)$ & $20(33.3)$ \\
\hline SS-CHX aged & $3(5.0)$ & $31(51.7)$ & - & $1(1.7)$ & $7(11.7)$ & $18(30.0)$ \\
\hline $\mathrm{SS}-\mathrm{O}_{3}$ aged & $3(5.0)$ & $40(66.7)$ & - & - & $2(3.3)$ & $15(25.0)$ \\
\hline NiTi-NaOCl aged & $1(1.7)$ & $20(33.3)$ & - & $9(15.0)$ & $15(25.0)$ & $15(25.0)$ \\
\hline NiTi-CHX aged & - & $42(70.0)$ & - & - & $10(16.7)$ & $8(13.3)$ \\
\hline $\mathrm{NiTiO}_{3}$ aged & $1(1.7)$ & 35 (58.3) & $1(1.7)$ & - & $3(5.0)$ & $20(33.3)$ \\
\hline
\end{tabular}

SS: Root canal preparation with stainless steel instruments-K-file; NiTi: Root canal preparation with K3 nickel-titanium instruments; $\mathrm{NaOCl}: 1 \%$ sodium hypochlorite; $\mathrm{CHX}: 2 \%$ chlorhexidine; $\mathrm{O}_{3}: 1.2 \%$ ozonated water; Immediate: Test with no aging; Aged: Test performed after 2 months of water storage at $37^{\circ} \mathrm{C}$ 
logical interaction. ${ }^{23-25}$ In agreement to this, Bitter et al described that with RelyX Unicem the smear layer did not dissolve consistently at the cement-dentin interface and hybridization of dentin was only detected sporadically.

However, an intense chemical interaction of RelyX Unicem with hydroxyapatite has been documented. ${ }^{24}$ This interaction is most probably based on chelation of the calcium ions by acid groups and produce chemical adhesion to hydroxyapatite in tooth structure. ${ }^{24}$ Chemical interactions may be effective inside the root canal, and indicate that this interaction might be more crucial for root dentine bonding than the ability of the same material to hybridize dentine. ${ }^{4}$ Therefore, an effective removal of the smear layer allowing that RelyX U100 becomes adapted to the dentine, with good interfacial continuity, can optimize physical interactions, such as van der Waals forces, hydrogen bridges and charge transfer, which enhances micromechanical retention and chemical bonding. ${ }^{22}$

Root canal preparation aims at the emptying, enlargement and sanitizing the root canal. ${ }^{20}$ The stainless-steel instruments have generally been used for this purpose. The nickel-titanium instruments have been suggested in order to facilitate curved RCP, due to the flexibility and super-elasticity. The quality of modeling, efficiency, less time of work and decrease of stress in professional are other qualities inherent in the preparation with $\mathrm{NiTi}$ instruments. ${ }^{26}$ The preparation with stainless steel instruments has allowed that walls have not been touched by the instruments. ${ }^{26}$ Since these instruments act as crapers, and not by excision of dentine, as occurs with NiTi instruments, it can be suggested a greater possibility of compaction of smear layer into dentinal tubules; featuring greater presence of smear plug, which probably was not completely removed even after the post space preparation. This may have acted as a barrier to penetration and interaction of cement with intraradicular dentine, which may be related to the decrease of bond strength observed in groups prepared with stainless steel instruments in the present study. It has been assumed that it is necessary to remove the smear layer and debris from the dentine canal walls and the initial part of dentinal tubules to increase retention when resin cement is used. ${ }^{27}$

Sodium hypochlorite is a halogenated compound routinely used in endodontics, and with high antimicrobial potential. However, it does not act on the inorganic portion of dentin, which constitutes great part of the smear layer. ${ }^{1,6,13}$ Ethylenediaminetetraacetic acid produces dentine demineralization and provides a cleaning of the root canal walls, improving the penetration of chemical substances and promoting a more intimate contact of the filling material with the root canal dentine. $1,6,13,16,28$ It acts on the inorganic components of the smear layer, leading to decalcification of the peri- and inter-tubular dentin. $1,6,13,16,28$

The compounds $\mathrm{NaOCl}$ and EDTA are often used in root canal treatment because they act in organic and inorganic content of the root canal, with remotion of the smear layer and exposition of the dentinal tubules. ${ }^{28}$ Probably, this fact may increase the penetration of the cement into the partially demineralized dentin structure, favoring the micromechanical retention and increasing the bond strength. ${ }^{16,25}$ Chlorhexidine and ozonated water, however, do not have the ability to dissolve organic tissues, and debris can remain adhered to root canal walls obstructing the dentinal tubules, which can negatively influence the bond to root dentine, as seen in the present study. ${ }^{12,20}$ In addition, as $\mathrm{NaOCl}$ acts on organic portion dissolution exposing the inorganic, this action may favor the chemical interactions between hydroxyapatite and cement, justifying the highest bond strength values found when this irrigant was used.

The effect of $\mathrm{NaOCl}$ on the bond strength of resin cements to intraradicular dentine has provided some discussion. Some studies have demonstrated benefit when this solution is used, whereas other studies described an adverse effect of this irrigant on bonding. ${ }^{11,13,16-19}$ The increase in bond strength has been explained by the removal of the collagen of the smear layer, which resulted in the rough surface of the dentine. On the other hand, the decrease in bond strength has been explained by the change of the redox potential of bonding substrate due to the residual $\mathrm{NaOCl}$. However, these studies present different methodologies from those used in the present study, regarding concentration and exposure time of $\mathrm{NaOCl}$, hindering appropriate comparison with the obtained results.

Ozonated water significantly reduced the bond strength to root canal. Ozone $\left(\mathrm{O}_{3}\right)$ is a highly reactive form of oxygen that is generated by passing oxygen through high voltage. ${ }^{20}$ It is a blue gas, containing three oxygen atoms, present antimicrobial power, irritant, toxic and unstable. ${ }^{20,29}$ However, because of its high instability, ozone rapidly turns into oxygen, which may inhibit the polymerization of the resin cement and thus reduce bond strength. ${ }^{12,20,29}$ Therefore, a possible interaction with initiator components of resin cements as well as a certain influence of the material properties, such as the inability to dissolve organic tissue, may explain the significant reduction in bond strength. ${ }^{12}$

Although fiber posts luted in root canals are not directly exposed to oral fluids, water storage is considered as ex vivo accelerated aging test for bonded interfaces. ${ }^{30,31}$ Studies have reported that the exposure of specimens to water for 1 month and 2 months significantly reduced 
fiber post-resin and fiber post-dentin bond strengths, respectively due to formation of microcracks in polymer networks as a consequence of water sorption; resulting in gaps at the post-adhesive interface and hydrolytic degradation of collagen fibers. ${ }^{30,31}$ In the present study, water artificial aging for 2 months significantly increased post retention. Probably, the aqueous challenge proposed in this study was not enough to negatively affect the resin cement RelyX U100 network, and as it is a self-etch self-adhesive system, collagen fibers could be completely covered by the resin phase and are inaccessible to water needed to effect collagenolysis. ${ }^{31}$

Increases in interfacial strength may be related to enhanced bonding ability or setting during water storage, stress relaxation by hygroscopic expansion as a consequence of water sorption during storage, or hygroscopic expansion of luting materials. ${ }^{32}$ The hygroscopic expansion of the resin cement, in particular, could have contributed to a greater adaptation of the cement to dentin substrate. A major contribution to retentive strength in push-out test is expected to occur as a consequence of the interfacial sliding friction resulting from application of a compressive force. ${ }^{32}$ Thus, the higher 2 months interfacial strengths achieved may have been caused by the increase in interfacial friction, due to the greater adaptation of the cement to dentine, consequent to hygroscopic expansion. ${ }^{32}$ It is important to emphasize that the applied method is a simplified model of accelerated aging which has been commonly performed for challenging resindentin adhesion. ${ }^{23,30}$

Bond strengths decreased significantly from cervical to apical post thirds, in agreement with findings from previous reports. ${ }^{14,33}$ Factors possibly associated with this decrease are: the difficulty of access to apical level of post space; the non-uniform adaptation of the bonding material to the deepest portion of the post space associated with possible limitations of cement flow, as the cement used in the present study has a high viscosity; the drop in light intensity with increasing distance affecting the degree of conversion of resin cement. ${ }^{14,22,23}$

In addition, the $\mathrm{C}$-factor, defined as the ratio of bonded to unbonded surface areas of cavities in a root canal is highly unfavorable and contributes to maximizing the polymerization stress of resin based materials along the root canal walls. ${ }^{14,15}$ Morris et al estimated that C-factors in root canals can range from 20 to 100, depending on the diameter and length of the root canal. ${ }^{13}$

Fractographic analysis provides important information that helps to predict the adhesive material performance. In the present study, confocal microscopy was used and appears to be a noteworthy alternative for failure modes analysis, since it is less time consuming and does not require any preparation of the specimens. ${ }^{21}$ In this study, there was predominance of adhesive failure between resin cement and root dentine in all groups (Table 4), which may be related to the reduced ability of dentine demineralization and hybridization of the self-adhesive cement; RelyX U100, and the highly unfavorable C-factor which maximizes polymerization contraction stresses and leads to debonding of resin from the canal wall. ${ }^{4,13-15,23,24}$

One of the limitations of this study was that the specimens were not submitted to thermal and mechanical cycling to simulate intra-oral conditions more precisely. Bovine teeth were used because it is difficult to collect and use human teeth for research purposes., ${ }^{3,33}$ Bovine teeth are easier to collect and tooth age can be standardized.,33 Moreover, similar properties between human and bovine teeth have been demonstrated..$^{34,35}$

Further studies need to be conducted to analyze the effects of different concentrations of $\mathrm{NaOCl}$; the association of a reversal agent, such as ascorbic acid or sodium ascorbate with ozonated water in order to reverse the oxidized dentine; and the increase of the artificial aging time on bond strength to intraradicular dentin.

\section{CONCLUSION}

Root canal preparation with NiTi instruments associated with $\mathrm{NaOCl}$ irrigation and EDTA increased the bond strength of fiberglass posts cemented with self-adhesive resin cement to intraradicular dentine. Water artificial aging for 2 months significantly increased post retention. There was a predominance of adhesive failures between resin cement and dentin in all groups.

\section{ACKNOWLEDGMENTS}

The authors deny conflicts of interest related to this study. The authors are indebted to Federal University of Uberlândia (Integrated Laboratory for Dental Research/UFU, Brazil) and Professor Dr Marcelo Emilio Beletti (Laboratory of Image Analysis, Histological Techniques and Microscopy/UFU, Brazil) for technical support. This study was supported by grants from the CAPES, FAPEMIG and CNPq (CNPq grants to CE \# 306394/2011-1).

\section{REFERENCES}

1. Cagidiaco MC, Goracci C, Garcia-Godoy F, Ferrari M. Clinical studies of fiber posts: a literature review. Int J Prosthod 2008 Jul-Aug;21(4):328-336.

2. Schwartz RS, Robbins JW. Post placement and restoration of endodontically treated teeth: a literature review. J Endod 2004 May;30(5):289-301.

3. Soares CJ, Pereira JC, Valdivia AD, Novais VR, Meneses MS. Influence of resin cement and post configuration on bond strength to root dentine. Int Endod J 2012 Feb;45(2):136-145. 
4. Bitter K, Paris S, Pfuertner C, Neumann K, Kielbassa AM. Morphological and bond strength evaluation of different resin cements to root dentin. Eur J Oral Sci 2009 Jun;117(3):326-333.

5. Lassila LVJ, Tanner J, Le-Bell AM, Narva K, Vallittu PK. Flexural properties of fiber reinforced root canal posts. Dent Mat 2004 Jan;20(1):29-36.

6. Cecchin D, Farina AP, Souza MA, Carlini-Júnior B, Ferraz CC. Effect of root canal sealers on bond strength of fibreglass posts cemented with self-adhesive resin cements. Int Endod J 2011 Apr;44(4):314-320.

7. Soares CJ, Santana FR, Castro CG, Santos-Filho PC, Soares PV, Qian F, Armstrong SR. Finite element analysis and bond strength of a glass post to intraradicular dentin: comparison between microtensile and push-out tests. Dent Mat 2008 Oct;24(10):1405-1411.

8. Ferrari M, Cagidiaco MC, Goracci C, Vichi A, Mason PN, Radovic I, Tay F. Long-term retrospective study of the clinical performance of fiber posts. Am J Dent 2007 Oct;20(5):287-291.

9. Jongsma LA, Kleverlaan CJ, Feilzer AJ. Influence of surface pretreatment of fiber posts on cement delamination. Dent Mat 2010 Sep;26(9):901-907.

10. Mjör IA, Smith MR, Ferrari M, Mannocci F. The structure of dentine in the apical region of human teeth. Int Endod J 2001 Jul;34(5):346-353.

11. Pelegrine RA, De Martin AS, Cunha RS, Pelegrine AA, da Silveira Bueno CE. Influence of chemical irrigants on the tensile bond strength of an adhesive system used to cement glass fiber posts to root dentin. Oral Surg Oral Med Oral Pathol Oral Radiol Endod 2010 Nov;110(5):e73-76.

12. Bitter K, Noetzel J, Volk C, Neumann K, Kielbassa A. Bond strength of fiber posts after the application of erbium:yttriumaluminum-garnet laser treatment and gaseous ozone to the root canal. J Endod 2008 Mar;34(3):306-309.

13. Morris MD, Lee KW, Agee KA, Bouillaguet S, Pashley DH. Effects of sodium hypochlorite and RC-prep on bond strength of resin cement to endodontic surfaces. J Endod 2001 Dec;27(12):753-757.

14. Goracci C, Tavares AU, Fabianelli A, Monticelli F, Raffaelli O, Cardoso PC, Tay F, Ferrari M. The adhesion between fiber posts and root canal walls: comparison between microtensile and push-out bond strength measurements. Eur J Oral Sci 2004 Aug;112(4):353-361.

15. Tay FR, Loushine RJ, Lambrechts P, Weller RN, Pashley DH. Geometric factors affecting dentin bonding in root canals: a theoretical modeling approach. J Endod 2005 Aug;31(8):584-589.

16. AriH, Yaşar E, BelliS. Effects of $\mathrm{NaOCl}$ on bond strengths of resin cements to root canal dentin. J Endod 2003 Apr;29(4):248-251.

17. Erdemir A, Ari H, Güngüneş H, Belli S. Effect of medications for root canal treatment on bonding to root canal dentin. J Endod 2004 Feb;30(2):113-116.

18. Hayashi M, Takahashi Y, Hirai M, Iwami Y, Imazato S, Ebisu S. Effect of endodontic irrigation on bonding of resin cement to radicular dentin. Eur J Oral Sci 2005 Feb;113(1):70-76.

19. Muniz L, Mathias P. The influence of sodium hypochlorite and root canal sealers on post retention in different dentin regions. Oper Dent 2005 Jul-Aug;30(4):533-539.

20. Estrela C, Estrela CR, Decurcio DA, Hollanda AC, Silva JÁ. Antimicrobial efficacy of ozonated water, gaseous ozone, sodium hypochlorite and chlorhexidine in infected human root canals. Int Endod J 2007 Feb;40(2):85-93.

21. Castellan CS, Santos-Filho PC, Soares PV, Soares CJ, Cardoso PE. Measuring bond strength between fiber post and root dentin: a comparison of different tests. J Adhes Dent 2010 Dec;12(6):477-485.

22. Silva RA, Coutinho M, Cardozo PI, Silva LA, Zorzatto JR. Conventional dual-cure versus self-adhesive resin cements in dentin bond integrity. J App Oral Sci 2011 Aug;19(4): 355-362.

23. De Munck J, Van Landuyt K, Peumans M, Poitevin A, Lambrechts P, Braem M, Van Meerbeek B. A critical review of the durability of adhesion to tooth tissue: methods and results. J Dent Res 2005 Feb;84(2):118-132.

24. Gerth HU, Dammaschke T, Züchner H, Schäfer E. Chemical analysis and bonding reaction of RelyX Unicem and Bifix composites-a comparative study. Dent Mat 2006 Oct;22(10):934-941.

25. Monticelli F, Osorio R, Mazzitelli C, Ferrari M, Toledano M. Limited decalcification/diffusion of self-adhesive cements into dentin. J Dent Res 2008 Oct;87(10):974-979.

26. Peters OA, Paqué F. Current developments in rotary root canal instrument technology and clinical use: a review. Quintessence Int 2010 Jun;41(6):479-488.

27. Serafino C, Gallina G, Cumbo E, Ferrari M. Surface debris of canal walls after post space preparation in endodontically treated teeth: a scanning electron microscopic study. Oral Surg Oral Med Oral Pathol Oral Radiol Endod 2004 Mar;97(3): 381-387.

28. Wu H, Hayashi M, Okamura K, Koytchev EV, Imazato S, Tanaka S, Tanaka Y, Sano H, Ebisu S. Effects of light penetration and smear layer removal on adhesion of postcores to root canal dentin by self-etching adhesives. Dent Mat 2009 Dec;25(12):1484-1492.

29. Stübinger S, Sader R, Filippi A. The use of ozone in dentistry and maxillofacial surgery: a review. Quintessence Int 2006 May;37(5):353-359.

30. Radovic I, Monticelli F, Papacchini F, Magni E, Cury AH, Vulicevic ZR, Ferrari M. Accelerated aging of adhesivemediated fiber post-resin composite bonds: A modeling approach. J Dent 2007 Aug;35(8):683-689.

31. Montanari M, Prati C, Piana G. Differential hydrolytic degradation of dentin bonds when luting carbon fiber posts to the root canal. Med Oral Patol Oral Cir Buc 2011 May 1;16(3):e411-417.

32. Sadek FT, Goracci C, Monticelli F, Grandini S, Cury AH, Tay F, Ferrari M. Immediate and 24 hours evaluation of the interfacial strengths of fiber posts. J Endod 2006 Dec;32(12):1174-1177.

33. Menezes MS, Queiroz EC, Campos RE, Martins LRM, Soares CJ. Influence of endodontic sealer cement on fiberglass post bond strength to root dentine. Int Endod J 2008 Jun; 41(6):476-484.

34. Dong CC, McComb D, Anderson JD, Tam LE. Effect of mode of polymerization of bonding agent on shear bond strength of auto cured resin composite luting cements. J Can Dent Ass 2003 Apr;69(4):229-234.

35. Nakamichi I, Iwaku M, Fusayama T. Bovine teeth as possible substitutes in the adhesion test. J Dent Res 1983 Oct;62(10):1076-1081. 